\title{
Electrochemical Studies of Copper, Nickel and a Cu55/Ni45 Alloy in
}

\section{Aqueous Sodium Acetate}

\author{
Reinaldo Simões Gonçalves, Denise Schermann Azambuja*, Alzira Maria \\ Serpa Lucho, Marlisa Piovesan Reche, Annelise M. Schmidt \\ Instituto de Química, Universidade Federal do Rio Grande do Sul, \\ 91501-970 Porto Alegre - RS, Brazil
}

Received: November 22, 2000; Revised: April 27, 2001

\begin{abstract}
This paper discusses the electrochemical behavior of copper, nickel and a copper/nickel alloy in aerated aqueous 0.10 and $1.0 \mathrm{~mol} \mathrm{~L}^{-1}$ sodium acetate. The data obtained from different electrochemical techniques were analyzed to determine the influence of $\mathrm{Ni}$ and $\mathrm{Cu}$ on the electrochemical processes of the alloy electrode. The shapes of the potentiodynamic I(E) curves of the alloy were found to be quite similar to those of the Ni voltamograms. Although the anodic current densities of $\mathrm{Ni}$ and the alloy increased with greater concentrations of acetate, the opposite effect occurred in $\mathrm{Cu}$. The impedance measurements taken at the open circuit potential revealed that the polarization resistance $(\mathrm{RP})$ of the electrodes decreased in the following order: $\mathrm{Ni}>$ Alloy $>\mathrm{Cu}$. With increasing concentrations of acetate, the $\mathrm{R}_{\mathrm{P}}$ of the alloy and the $\mathrm{Cu}$ increased while that of the Ni electrode decreased.
\end{abstract}

Keywords: acetate, copper/nickel, corrosion

\section{Introduction}

The literature on the electrochemical behavior of copper in acidic and basic media is quite extensive, since many technological applications require knowledge of these processes. Copper and copper alloys are widely used in practical applications due to their corrosion resistance and antifouling properties. The most important groups of copper alloys are brasses, bronzes, aluminum bronzes and cupronickels. Copper-nickel alloys are widely used in marine environments owing to their resistance to corrosion in saline solutions. Although the initial corrosion rate of copper and its alloys may be high, it decreases as protective product layers are formed. The corrosion resistance provided by a layer of reaction product varies according to the alloy and the composition of the electrolytic solution, and the thickness and electrical properties of a passive film are dependent on this composition. Electrodissolution of copper is a highly complex process and the composition of anodically formed layers depends on the nature of the electrolyte, the potential disturbance program, anodization time and mass transport ${ }^{1-4}$. Despite exhaustive studies devoted to this subject with the purpose of elucidating the mechanism of passivity in sulphate ${ }^{5}$ and chloride ${ }^{6}$, very little information is available concerning the mechanism of copper dissolution in quasi-neutral aqueous solutions containing acetate anions. Despite the scarcity of available data on this subject, a comprehensive examination of the literature uncovered findings to the effect that the presence of acetate enhances the corrosion rate of copper ${ }^{7}$ and that stress corrosion cracking can be induced in $\alpha$-brass by sodium acetate ${ }^{8}$. The corrosion of a Cu10Ni alloy in $1 \mathrm{~mol} \mathrm{~L}^{-1}$ acetate buffer with $\mathrm{pH} 5.8$ in the presence of benzotriazole (BTA) as a corrosion inhibitor ${ }^{9}$ was recently reported. The present study focuses on the electrochemical behavior of $\mathrm{Cu}, \mathrm{Ni}$ and $\mathrm{Cu} 55 \mathrm{Ni} 45$ alloy in aerated sodium acetate solutions with $\mathrm{pH} 5.0$ using open circuit measurements, and voltametric and impedance techniques.

\section{Experimental}

Electrochemical experiments were carried out on a three-electrode electrochemical cell with a platinum 
counter-electrode. The reference was a saturated calomel electrode (SCE) to which all the potentials mentioned herein are referred. The working electrodes were made from:

a) a $99.7 \%$ pure copper sheet (Merck) and $99.5 \%$ pure nickel foil (Carlo Erba); samples were cut off in rectangles; and

b) a copper/nickel (Cu55/Ni45) wire alloy (Goodfellow).

All the electrodes were polished with aluminum oxide powder, degreased with carbon tetrachloride and dried. Details of the preparation of such electrodes are described elsewhere ${ }^{10}$.

The aqueous $0.10 \mathrm{~mol} \mathrm{~L}^{-1}$ and $1.0 \mathrm{~mol} \mathrm{~L}^{-1}$ sodium acetate solutions were prepared from an analytical grade compound and deionized water. All the experiments were made in aerated solutions. The temperature was kept at $25^{\circ} \mathrm{C}$, and $\mathrm{pH}$ was adjusted to 5.0 using glacial acetic acid.

The electronic arrangement consisted of a PAR 366 bi-potentiostat and an X-Y RB400-ECB recorder. Impedance experiments were made with an Autolab/Echo Chemie - PGSTAT30, and galvanostatic tests with a TECTROL - TCH 1000-005 DC power source. Potentiometric studies under open-circuit conditions were carried out using a digital MINIPA-ET2002 multimeter. The impedance measurements were taken in a frequency range of $100 \mathrm{kHz}$ to $10 \mathrm{mHz}$, using a $10 \mathrm{mV}$ amplitude of sinusoidal voltage.

\section{Results and Discussion}

\subsection{Open circuit measurements}

After polished with aluminum oxide powder, degreased with carbon tetrachloride and dried, the electrodes were immersed in the electrolytic solution and the electrode potential measured against the reference SCE. Figure 1 shows the variation of the open-circuit potential ( $\left.E_{\text {corr }}\right)$ with time, for copper, nickel and copper/nickel alloy in aerated sodium acetate $1.0 \mathrm{~mol} \mathrm{~L}^{-1}, \mathrm{pH}=5.0$. The $\mathrm{E}_{\text {corr }}$ of the $\mathrm{Cu}$ electrode stabilized at a more positive value than did that of the other metals. On the other hand, the $\mathrm{E}_{\text {corr }}$ of the $\mathrm{Ni}$ electrode reached a more negative steady state than the other electrodes. The open-circuit potential of the copper/nickel alloy stabilized at a value close to that of the

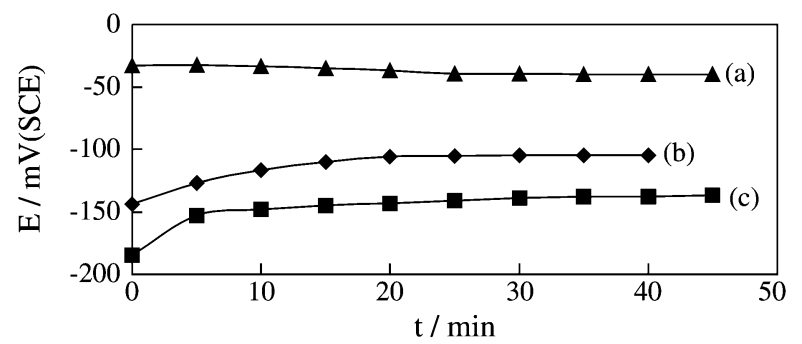

Figure 1. Corrosion potential at open-circuit for a) copper; b) copper/nickel alloy and c) nickel, in aerated $1.0 \mathrm{~mol} \mathrm{~L}^{-1}$ a sodium acetate, under stirring. nickel $\mathrm{E}_{\text {corr }}$, suggesting a preferential formation of nickel oxide film on the metal surface.

\subsection{Cyclic voltametry}

The same pre-treatment was applied to the electrodes used in these experiments as the one described earlier. To improve the reproducibility of the data, a potential program was applied before each experiment, in the potential range at $0.050 \mathrm{Vs}^{-1}$ up to the point of coincidence of the voltamograms.

Figure 2a shows the voltamograms of pure nickel in 1.0 and $0.1 \mathrm{~mol} \mathrm{~L}-1$ sodium acetate solutions at $0.050 \mathrm{Vs}^{-1}$. Cathodic currents associated with electroreduction processes appear in the potential range of $-0.6 \mathrm{~V}$ to $0.0 \mathrm{~V}$. The current densities of the electrode electrooxidation are visible between $0.25 \mathrm{~V}$ and $1.0 \mathrm{~V}$.

Some authors suggest that anodic reactions in the last potential range begin with a direct interaction between the electroreduced nickel surface and water, yielding adsorbed $\mathrm{OH}$ on nickel, $\mathrm{Ni}(\mathrm{OH})_{\mathrm{ad}}$, and protons as initial products ${ }^{11}$.

$$
\begin{array}{r}
{[\mathrm{Ni}]_{\mathrm{k}}+\mathrm{H}_{2} \mathrm{O} \leftrightarrow[\mathrm{Ni}] \mathrm{k}\left(\mathrm{H}_{2} \mathrm{O}\right)_{\mathrm{ad}} \leftrightarrow[\mathrm{Ni}]_{\mathrm{k}-1} \mathrm{Ni}(\mathrm{OH})_{\mathrm{ad}}} \\
+\mathrm{H}^{+}{ }_{\mathrm{aq}}+\mathrm{e}^{-}
\end{array}
$$
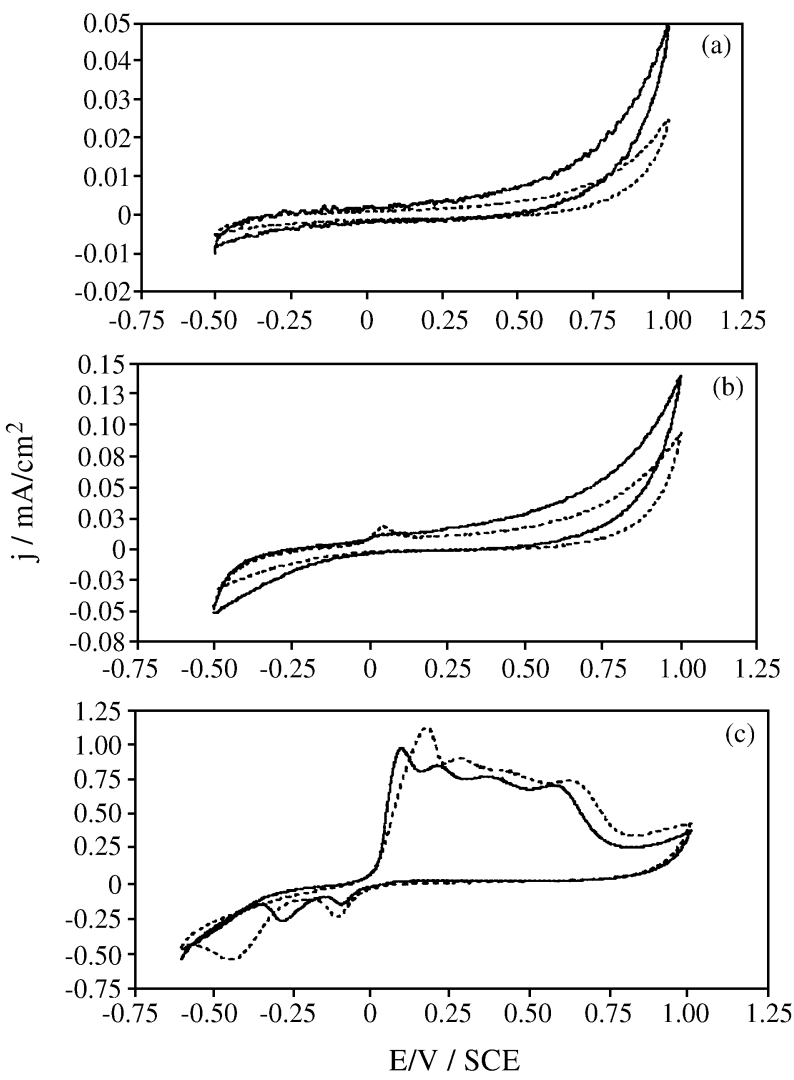

Figure 2. Cyclic voltammograms in aerated sodium acetate: (----) $0.10 \mathrm{~mol} \mathrm{~L}^{-1}$ and (—) $1.0 \mathrm{~mol} \mathrm{~L}^{-1}$, at $\mathrm{v}=0.05 \mathrm{~V} / \mathrm{s}$, (a)for pure nickel, (b) for Cu55/Ni45 alloy and (c) for pure copper. 
The following electron transfer step, according to the authors $^{(9)}$, corresponds to the formation of the $(\mathrm{NiOH})^{+}$ species, which plays a critical role in the formation of soluble $\mathrm{Ni}(\mathrm{II})$ species.

It is generally assumed that anions such as $\mathrm{HSO}_{4}$ - and $\mathrm{ClO}_{4}$ - do not participate directly in the anodic dissolution of nickel. However, all anions are assumed to participate in the formation of adsorbed intermediates ${ }^{12}$. In the active region, the order of effectiveness of a catalyst is probably:

$$
\mathrm{Cl}^{-}>\mathrm{Br}^{-}>\mathrm{I}^{-}>\mathrm{SO}_{4}^{-}>\mathrm{ClO}_{4}^{-}>\mathrm{CH}_{3} \mathrm{COO}^{-}
$$

The role of the $\mathrm{CH}_{3} \mathrm{COO}^{-}$anion in the reaction mechanism is clearly evidenced in a comparison of the voltamograms. Anodic current densities increase as the acetate anion concentration increases, meaning that the dissolution of $\mathrm{Ni}$ increases proportionally to the acetate concentration.

Figure $2 \mathrm{c}$ shows the influence of acetate in the copper's cyclic voltamograms run from $E_{i}=-0.6 \mathrm{~V}$ to $E_{\mathrm{f}}=1.0 \mathrm{~V}$ (SCE), at a $0.05 \mathrm{Vs}^{-1}$ sweep rate, with a stationary electrode in $0.1 \mathrm{~mol} \mathrm{~L}^{-1}$ acetate (dashed line) and $1.0 \mathrm{~mol} \mathrm{~L}^{-1}$ (solid line) solutions. The anodic scan in $0.1 \mathrm{~mol} \mathrm{~L}^{-1}$ acetate displays four peaks followed by a sharp drop in the current at around $0.5 \mathrm{~V}$. This potential was ascribed to the Flade potential $\left(\mathrm{E}_{\mathrm{F}}\right)$, similarly to what was previously reported ${ }^{13}$. According to thermodynamic data ${ }^{14}$, these anodic processes can be ascribed to a first oxidation process from $\mathrm{Cu}(0)$ to $\mathrm{Cu}(\mathrm{I})$, followed by a second stage yielding $\mathrm{Cu}(\mathrm{II})$, as already reported in the literature ${ }^{15}$. Two small cathodic peaks at $-0.10 \mathrm{~V}$ and $-0.40 \mathrm{~V}$ were observed in the reverse direction of the scan. We assume that these two peaks relate to the electroreduction of the copper oxide formed on the electrode surface. Upon increasing the concentration of acetate (solid line), the potential of the anodic peaks as well as $E_{F}$ shift toward more negative values, indicating that the dissolution/precipitation processes were anticipated. Using more concentrated acetate solutions, a decrease in the current was observed for the first anodic peak. This effect may be caused by acetate adsorption on the electrode surface blocking the process of water adsorption, which is involved on the electrooxidation mechanism.

Figure $2 \mathrm{~b}$ presents the $\mathrm{I}(\mathrm{E})$ curves for $\mathrm{Cu} / \mathrm{Ni}$ alloy in aqueous sodium acetate solutions in two concentrations. The electrochemical behavior of the alloy is similar to that of pure nickel. Experimental evidence confirms that only alloys containing less than $30 \%$ of nickel have an electrochemical behavior similar to that of copper itself ${ }^{16}$. These observations indicate that the presence of copper has little effect on the electrochemical behavior of the alloy studied here.

The slow sweep rates used in these experiments aimed to induce a quasi-steady state condition, which allows for calculation of the current density values taken from the voltamograms during cathodic and anodic polarization.
Figure 3 shows these data for copper in two sodium acetate concentrations as polarization curves close to the potential at which the current was null. The corrosion potential ( $\left.\mathrm{E}_{\text {corr }}\right)$ values were found to be dependent on the concentration of salt, i.e., around $-170 \mathrm{mV}(\mathrm{SCE})$ for $0.10 \mathrm{M}$ and $-110 \mathrm{mV}$ (SCE) for 1.0 M sodium acetate. The corrosion current density ( $\mathrm{i}_{\text {corr }}$ ) values were found to be lower in 0.10 $\mathrm{M}$ than in $1.0 \mathrm{M}$ sodium acetate. The same dependence was observed in nickel and copper/nickel alloy, with an $\mathrm{i}_{\text {corr }}$ value ten times lower than that found for the copper data.

\subsection{Impedance measurements}

Impedance (EIS) measurements were taken at the open circuit potential (OCP) after $10 \mathrm{~min}$ and $60 \mathrm{~min}$ immersion time to assess the effect of the concentration of sodium acetate on the electrochemical behavior of nickel, copper and copper/nickel alloy in an aqueous solution.

Figure 4 shows the Nyquist plot for a copper electrode at the OCP in 0.1 and $1.0 \mathrm{~mol} \mathrm{~L}^{-1}$ acetate solutions after 60 min immersion. A greater concentration of acetate caused the polarization resistance to increase and a capacitive behavior was detected, suggesting that acetate anion adsorption occurs on the electrode, favoring the blockage of active sites on the metal surface.

The EIS experiments for pure nickel (Fig. 5) run at the OCP, after 60 min of immersion time, revealed that metal

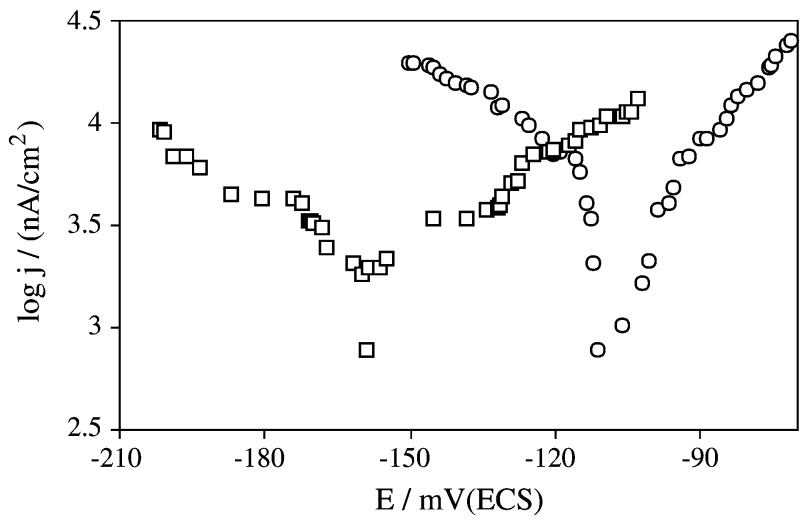

Figure 3. Polarization curves of copper in aerated sodium acetate (o) $0.10 \mathrm{~mol} \mathrm{~L}^{-1}$ and $(\square) 1.0 \mathrm{~mol} \mathrm{~L}^{-1}$, taken from the voltammograms.

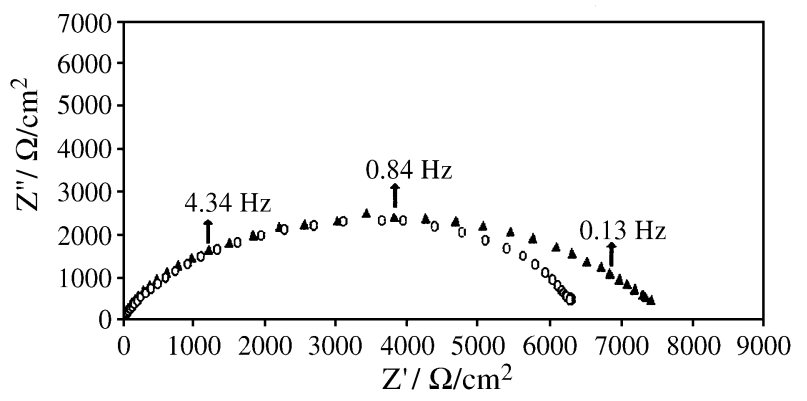

Figure 4. Nyquist diagram for pure copper at open-circuit potential (OCP), after $60 \mathrm{~min}$ of immersion in aerated aqueous sodium acetate: (o) $0.10 \mathrm{~mol} \mathrm{~L}^{-1}$ and $(\mathbf{\Delta}) 1.0 \mathrm{~mol} \mathrm{~L}^{-1}$. 
electrodissolution in $0,1 \mathrm{~mol} \mathrm{~L}^{-1}$ acetate solution was under diffusion control, and a capacitive behavior was detected in $1 \mathrm{~mol} \mathrm{~L}^{-1}$. In this case, polarization resistance increased when the concentration of acetate was decreased.

The Nyquist diagrams for the copper/nickel alloy electrode in an acetate solution were measured at the OCP after 60 min immersion time (Fig. 6). These diagrams were characterized by depressed capacitive loops, with the theoretical center located below the real axis, reflecting a surface inhomogeneity of structural or interfacial origin, such as those found in the adsorption processes. These results are consistent with those reported in the literature ${ }^{17}$. Two time constants can be used to interpret these EIS plots. The high frequency constant corresponds to a porous layer, whereas the second constant represents a more resistant film. This behavior may have been caused by the formation of intermediate species adsorbed on the electrode surface ${ }^{18}$.

Figure 7 shows the EIS diagrams for the alloy electrode after 10 min of immersion in 0.10 and $1.0 \mathrm{~mol} \mathrm{~L}^{-1}$ sodium acetate solutions. A comparison between the data of Figs. 6 and 7 shows that decreased immersion times heightened the film's resistance. The electrical equivalent circuit (EEC) proposed to fit the experimental data, which is shown in the insert of Fig. 7, consists of the electrolytic resistance, $\mathrm{R}_{\mathrm{S}}$, in a serial connection with two time constants. The first constant, at a high frequency, corresponds to the external layer, with $\mathrm{R}_{1}$ representing the resistance and $\mathrm{C}_{1}$ the capacitance of this layer. The internal layer is char-

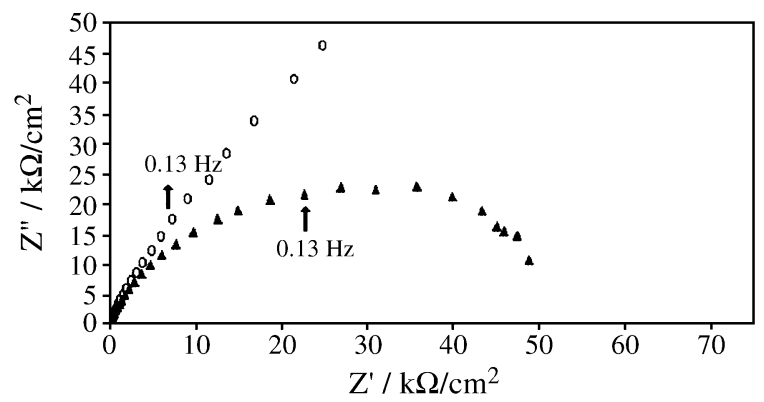

Figure 5. Nyquist diagram for pure nickel, at OCP, after $60 \mathrm{~min}$ of immersion in aerated aqueous sodium acetate: (o) $0.10 \mathrm{~mol} \mathrm{~L}^{-1}$ and (A) $1.0 \mathrm{~mol} \mathrm{~L}^{-1}$.

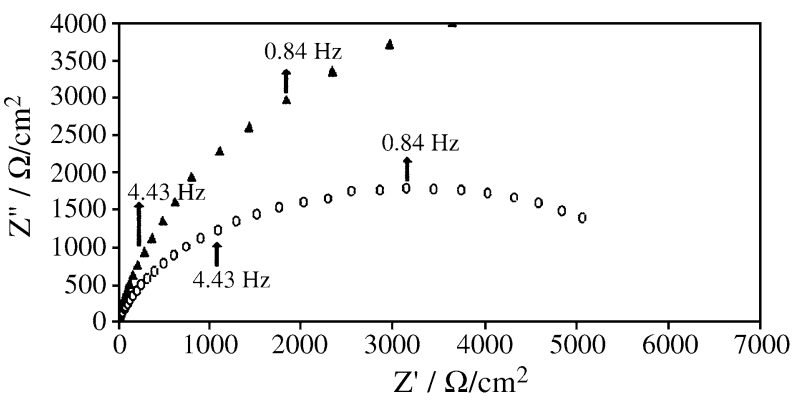

Figure 6. Nyquist diagram for copper/nickel alloy at OCP, after $60 \mathrm{~min}$ of immersion in aerated aqueous sodium acetate: (o) $0.10 \mathrm{~mol} \mathrm{~L}^{-1}$ and (A) $1.0 \mathrm{~mol} \mathrm{~L}^{-1}$.

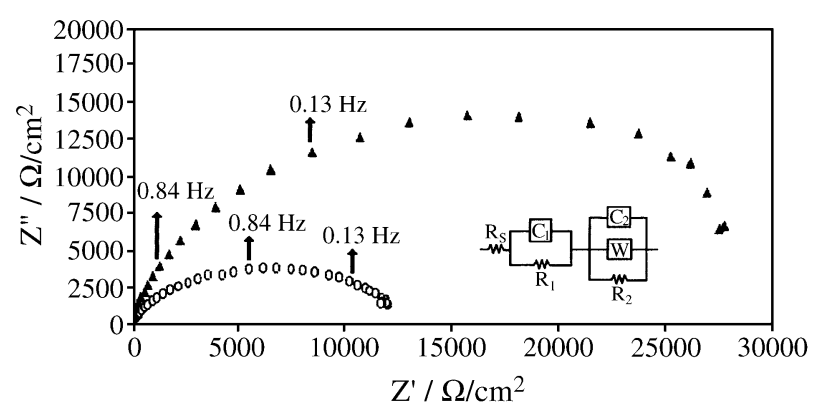

Figure 7. Nyquist diagram for copper/nickel alloy at OCP, after $10 \mathrm{~min}$ of immersion in aerated aqueous sodium acetate: (o) $0.10 \mathrm{~mol} \mathrm{~L}^{-1}$ and (A) $1.0 \mathrm{~mol} \mathrm{~L}^{-1}$. The inset: Electrical equivalent circuit used to fit the EIS data.

acterized by a resistance, $\mathrm{R}_{2}$, a capacitance, $\mathrm{C}_{2}$, and a Warburg impedance element, W. The Warburg impedance, $\mathrm{W}$, takes into account a diffusion process similar to those found in corroding systems ${ }^{19}$. The corresponding fitting parameters used are given in Table 1.

Figure 8 shows the Bode plots for copper, nickel and the alloy electrodes in a $0.1 \mathrm{~mol} \mathrm{~L}^{-1}$ acetate solution after 10 min of immersion. A comparison of the EIS diagrams indicates that the film layer formed on the alloy is similar to that of copper, but with an alloy corrosion resistance greater than that of copper. These results are evidence that acetate anions preferentially promote the dissolution of

Table 1. Fitting parameters used to simulate the EIS data for copper/nickel electrode in $0.1 \mathrm{~mol} \mathrm{~L}^{-1}$ and $1.0 \mathrm{~mol} \mathrm{~L}^{-1}$ acetate solution at open circuit potential, after $10 \mathrm{~min}$ immersion time.

\begin{tabular}{lcc}
\hline Acetate solution & $0.1 \mathrm{~mol} \mathrm{~L}^{-1}$ & $1.0 \mathrm{~mol} \mathrm{~L}^{-1}$ \\
\hline $\mathrm{R}_{\mathrm{S}}\left(\Omega \mathrm{cm}^{2}\right)$ & 20.07 & 16.6 \\
$\mathrm{R}_{1}\left(\Omega \mathrm{cm}^{2}\right)$ & 11.9 & 52.5 \\
$\mathrm{C}_{1}\left(\mu \mathrm{F} \mathrm{cm}{ }^{-2}\right)$ & 5.2 & 10.1 \\
$\mathrm{R}_{2}\left(\mathrm{k} \Omega \mathrm{cm}^{2}\right)$ & 15.59 & 50.7 \\
$\mathrm{C}_{2}\left(\mu \mathrm{F} \mathrm{cm} \mathrm{cm}^{-2}\right)$ & 11 & 31.5 \\
$10^{4} \mathrm{~W}\left(\Omega^{-1} \mathrm{~s}^{0.5} \mathrm{~cm}^{-2}\right)$ & 0.39 & 0.48 \\
\hline
\end{tabular}

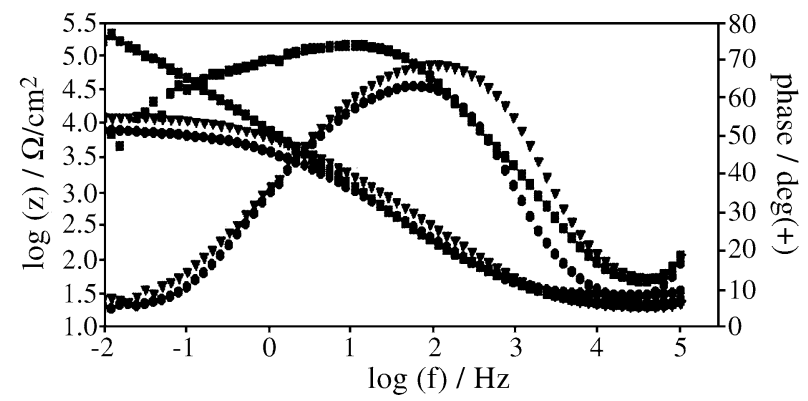

Figure 8. Bode diagram for pure copper $(\bullet)$, pure nickel $(\mathbf{\square})$ and copper/nickel alloy $(\boldsymbol{\nabla})$ at OCP, after $10 \mathrm{~min}$ of immersion in aerated $1.0 \mathrm{~mol} \mathrm{~L}^{-1}$ sodium acetate aqueous solution. 
nickel rather than of copper. Thus, a copper-rich layer is formed at the electrode surface, and the resistance and capacitance of this layer are influenced by the concentration of acetate.

\section{Conclusions}

The data obtained by open circuit measurements and voltametry confirmed that the electrochemical behavior of nickel and copper/nickel alloy were similar. In addition, preferential dissolution of the nickel component took place under anodic polarization. These results suggest that the presence of nickel in the alloy induces the electroactivity of the metal.

The film resistance formed on the copper and copper/nickel alloy at the open circuit potential increased with higher acetate concentrations. In contrast, the opposite behavior was detected in the nickel electrode. The corrosion resistance of the alloy, at the open circuit potential, was higher than that of copper and lower than that of nickel. On the other hand, the data taken from different electrochemical methods demonstrated that an adsorption process, which was influenced by the concentration of acetate, took place on the electrode surfaces.

\section{Acknowledgements}

The authors thanks to CAPES, CNPq and FAPERGS for financial support.

\section{References}

1. Souto R. M., Gonzalez S., Salvarezza A. J., Arvia A. J., Electrochim. Acta, v. 39, p. 2619 (1994).

2. Crundwell F. K., Electrochim. Acta, v. 37, p. 2707 (1992).

3. Lee H. P., Nobe K., Pearlstein J., J. Electrochem. Soc., v. 132 , p. 1031 (1985).
4. Moreira A. H., Benedetti A. V., Sumodjo P. T. A., Electrochim. Acta, v. 38, p. 981 (1993).

5. Uhlig, H., Electrochim. Acta, v.16, p.1939 (1971).

6. Walton, M. E.; Brook, P. A., Corros. Sci., v. 17, p.317 (1977).

7. Dewald H. D., Parmananda P., Rollins R. W., J. Electroanal. Chem., v. 306, p. 297 (1991).

8. Parkins, R. N., Holroyd N. J. H., Corrosion, v. 38, p. 245 (1982).

9. Babic R., Metikos-Hukovic M., Loncar M., Electrochim. Acta, v. 44, p. 2413 (1999).

10. Vendrame, Z. B., Gonçalves, R. S., J. Braz. Chem. Soc., v. 9, p. 441 (1998).

11. Barbosa, M. R., Real, S. G.; Vilche, J.R.; Arvia, A. J., J. Electrochem. Soc., v. 135, p. 1077 (1988).

12. Saraby-Reintjes, A., Electrochim. Acta, v. 30, p. 387 (1985).

13. Mostafa, S. N., Mourad, M. Y.; Seliman, S. A., J. Electroanal. Chem,. v. 130, p. 221 (1981).

14. Pourbaix, M. Atlas of Electrochemical Equilibria in Aqueous Solutions, NACE, Houston, 1974.

15. Kremer, E., Azambuja, D. S., J. Braz. Chem. Soc. v. 8, p. 165 (1997).

16. Saraby-Reintjes, A., Electrochim. Acta, v. 30, p. 403 (1985).

17. Hack, H.; Pickering, H., Electrochemical Impedance: Analysis and Interpretation, ASTM STP 1188, Scully, J.R., Silverman, D.D., Kendig, M.W., eds., pg. 220, 1993.

18. Jüttner, K. Electrochim. Acta, v. 35, p. 1501, 1990.

19. Bard,A.J.,Faulkner,L.R., Electrochemical Methods.Fundamentals and Applications. John Wiley \& Sons, 1980, pg.352. 